\title{
Does Toxoplasma gondii infection affect cognitive function? A case control study
}

\author{
Wojciech Guenter ${ }^{1}$, Maciej Bieliński ${ }^{1,3}$, Aleksander Deptuła ${ }^{2}$, Patrycja Zalas-Więcek ${ }^{2}$, \\ Małgorzata Piskunowicz ${ }^{1}$, Krzysztof Szwed ${ }^{1}$, Adam Buciński ${ }^{4}$, Eugenia Gospodarek ${ }^{2}$ and Alina Borkowska ${ }^{1}$
}

\author{
${ }^{1}$ Chair and Department of Clinical Neuropsychology, Nicolaus Copernicus University, Collegium Medicum, M. Skłodowskiej- \\ Curie 9, 85-094 Bydgoszcz, Poland; \\ ${ }^{2}$ Chair and Department of Microbiology, Nicolaus Copernicus University, Collegium Medicum, M. Skłodowskiej-Curie 9, 85-094 \\ Bydgoszcz, Poland; \\ ${ }^{3}$ Division of Vascular Diseases and Internal Medicine, Dr Jan Biziel University Hospital No. 2, Ujejskiego 75, 85-168 Bydgoszcz, \\ Poland; \\ ${ }^{4}$ Department of Biopharmacy, Nicolaus Copernicus University, Collegium Medicum, A. Jurasza 2, 85-089 Bydgoszcz, Poland
}

\begin{abstract}
According to studies, latent Toxoplasma gondii infection may affect several functions of the human brain. Here we search for the association between latent toxoplasmosis and cognitive performance. We tested 70 individuals for latent $T$. gondii infection. There were 26 Toxoplasma-infected subjects and 44 Toxoplasma-free subjects. Within these two groups we assessed cognitive performance using a set of standardized, widely recognized neuropsychological tests: Trail Making Test, Stroop Test, Verbal Fluency Test, Digit Span Test and N-back test. The relationship between chronic toxoplasmosis and cognitive performance was assessed, with adjustment for age and sex. Patients with latent toxoplasmosis performed worse on one neuropsychological test, N-back Test - percentage of correct answers $(\beta-8.08 ; 95 \% \mathrm{CI}-15.64$ to $-0.53 ; \mathrm{p}<0.05)$ compared to seronegative patients. However, after adjustment for age and sex, no statistically significant associations between latent toxoplasmosis and the scores on any cognitive tests were noticed. As statistically significant relationship was not observed, this study does not confirm that chronic latent $T$. gondii infection affects cognition.
\end{abstract}

Keywords: Toxoplasma gondii, latent toxoplasmosis, cognitive function, cognitive impairment, neuropsychological tests

Toxoplasma gondii Nicolle et Manceaux, 1908 is a neurotropic protozoan parasite that infects $20-60 \%$ of the population in most countries (Tenter et al. 2000). The proportion of people affected by this microorganism varies depending on many factors. Testing over 17 thousand people in the USA revealed the presence of specific antibodies in $10.8 \%$ of subjects (Jones et al. 2007). Examining over 2 thousand pregnant women in the capital of Poland shown an increased level of antibodies in 36.1\% of patients (Niemiec et al. 2002). Toxoplasmosis can be transmitted to humans by ingestion of cysts in raw or inadequately cooked infected meat, by ingestion of cats faeces, or transplacentally.

Although T. gondii infection is widely spread, overt disease symptoms such as encephalitis or chorioretinitis are uncommon and occur only during immune suppression. The acquired acute toxoplasmosis is characterized by rapid reproduction of tachyzoites in cells of different tissues. In immunocompetent subjects infection is asymptomatic or causes mild symptoms, similar to those of common viral and bacterial diseases (Montoya and Liesenfeld 2004).

Within weeks or months, acute infection turns into latent toxoplasmosis characterized by the life-long presence of the dormant cysts in the muscular and neural tissues and anamnestic concentrations of anti-Toxoplasma antibodies in immunocompetent subjects (Remington and Krahenbuhl 1982, Lyons et al. 2002). Although chronic toxoplasmosis is considered asymptomatic (Markell et al. 1999), its neurotropic nature makes $T$. gondii infection a potential cause of changes in the functioning of the brain

According to studies, T. gondii parasites have the ability to diminish learning capacity (Witting 1979) and alter behaviour in infected rodents (Hay et al. 1983, Skallová et al. 2006, Hermes et al. 2008, Kannan et al. 2010), especially elimination of the aversion to odour of cat urine (Vyas et al. 2007, Kannan et al. 2010). The parasite benefits from these changes through enhanced transmission rate. Intermediate hosts (e.g. rats) are more likely to be 
consumed by definitive hosts (cats). Infected rats are significantly more likely to be captured in live traps (Webster et al. 1994). The mechanisms of such behavioural changes remain unknown. However, some mechanisms by which $T$. gondii affects the brain have been studied and can be related to immunological reaction towards the dormant cysts (Hermes et al. 2008) and to some changes in dopaminergic transmission (Stibbs 1985, Skallová et al. 2006).

As latent toxoplasmosis is highly prevalent within many populations, possible influence on human behaviour and cognitive functions could have significant clinical implications. There are studies showing that latent $T$. gondii infection affects the human brain. It was noticed that the infected children had on average a lower IQ than the controls (Alford et al. 1974) and that subclinical chronic toxoplasmosis is an important component in the aetiology of mental retardation in school children (Caiaffa et al. 1993). Toxoplasma gondii also affects the ability for long-term mental concentration (Havlíček et al. 2001). Drivers infected with $T$. gondii are more likely to cause traffic accidents (Yereli et al. 2006, Flegr et al. 2009). The influence of latent $T$. gondii infection on mental diseases has also been studied. Researches support the theory that chronic toxoplasmosis may have a role in the aetiology of schizophrenia (Wang et al. 2006, Cetinkaya et al. 2007, Tamer et al. 2008) and obsessive-compulsive disorder (Miman et al. 2010). This topic is also discussed in the review of Fekadu et al. (2010). Furthermore, analyses show some differences in personality and temperament profiles between Toxoplasma-positive and Toxoplasma-negative subjects (Flegr and Hrdý 1994), especially in case of novelty seeking (Flegr et al. 2000, 2003, Skallová et al. 2005).

To our knowledge, in the studies on the impact of T. gondii infection on cognitive functioning, a diverse battery of cognitive tests has not been used. The aim of this study was to verify the hypothesis that latent toxoplasmosis can influence the cognitive performance using a set of widely recognized neuropsychological tests. For this purpose, a group of volunteers was tested for latent toxoplasmosis, a battery of cognitive tests was performed and the performance of infected and uninfected participants was compared.

\section{MATERIALS AND METHODS}

\section{Subjects}

A sample of 80 individuals responded to advertisements on the Internet and posters. These individuals were invited to take part in the study. Seventy participants completed the study. There were 14 males and 56 females. They were between 21 and 53 years of age, and had completed a minimum of 12 years of education. Participants took a battery of cognitive tests, afterwards the venous blood was sampled for measuring anti-T. gondii $\operatorname{IgG}$ and $\operatorname{IgM}$ antibody levels. Anti- $T$. gondii IgM antibody levels were measured to exclude acute $T$. gondii infection. IgM antibody was not elevated in any of the samples. After measuring T. gondii antibody levels we singled out 26 individuals with
IgG antibody levels above $35 \mathrm{IU} / \mathrm{ml}$ - seropositive participants. These account for $37 \%$ of all participants. For 44 individuals antibody test was negative - seronegative participants. These account for $63 \%$. The average age of seropositive individuals was 31.4 years of age (SD 8.4) and that of seronegative individuals was 24.9 years of age (SD 5.1). Seropositive group contained 6 males and 20 females, seronegative group contained 8 males and 36 females.

\section{Measures of antibody levels}

Serum antibodies levels against Toxoplasma gondii were evaluated in IgM and IgG classes using Meddens ELISA kits (Meddens Diagnostics BV, The Netherlands) according to the manufacturers' instructions. For the IgM class the assay was performed qualitatively and for the IgG quantitatively based on the calibration curve obtained for the standards included in the kit. In IgG antibody class, samples were considered as reactive if antibodies level exceeded $35 \mathrm{IU} / \mathrm{ml}$, equivocal - 30-35 IU/ml, and negative below $30 \mathrm{IU} / \mathrm{ml}$. All samples and standards were assayed in duplicate. In all performed assays validation criteria were met.

\section{Cognitive testing}

Cognitive function was assessed with a battery of standardized, widely employed neuropsychological tests. The set of tests measured performance in specific domains of interest. The chosen battery was composed of: Trail Making Test (TMT), Stroop Test, Verbal Fluency Test, Digit Span Test and N-back test.

TMT was used to assess psychomotor speed (visual motor speed) and working memory. The task requires participants to draw a line connecting 25 serial targets on a sheet of paper. In the first part (TMT A) targets are all numbers $(1,2,3$, etc.), in the second part (TMT B) the subjects alternate between numbers and letters (1, A, 2, B, etc.). The measure of performance is the time needed to complete the test.

To assess cognitive flexibility, the ability to monitor performance and inhibit incorrect automatic responses, which is an aspect of executive functioning, the Stroop Test was employed. During the first part of the test (Stroop Test I), the participant is required to read names of fifty colours printed in black ink, during the second part (Stroop Test II) the participant is asked to name the colour of the ink used to print the same names, while the colour of the ink and the printed name of the colour differ. The measure of performance is the time needed to complete the task.

Some aspects of executive functioning were assessed using Verbal Fluency Test - letter variant. In this test the participant is instructed to say as many words starting with a given letter as possible (without using proper names) during 60 seconds. The task is performed with three letters: "f", "a" and "s" consecutively. The measure of performance is the number of correctly generated words.

Digit Span is a subtest from Wechsler Adult Intelligence Scale. Digit Span Forwards (participant repeats series of digits) was used to assess short-term audioverbal memory. Digit Span Backwards (participant repeats series of digits backwards) was used to assess audioverbal working memory. The measure of performance is the number of correctly repeated series of numbers in both parts of the test.

Visuospatial working memory and reaction time were also assessed using N-back test. There is a sequence of digits presented on the computer screen and the participant is required to name the preceding digit while the current one is being pre- 
sented. The measure of performance is the percentage of correct answers and the reaction time.

\section{Statistical analysis}

STATISTICA 9 software package (StatSoft Inc., Tulsa, OK, USA) was used for statistical analysis. For all the assessed parameters, the arithmetic mean, median and standard deviation were calculated. The normality of the distribution of the assessed parameters was verified using the Shapiro-Wilk test. The homogeneity of variance in the study group was assessed using the Levene's test. The $P$ value of 0.05 was adopted as the critical level of significance. The statistical significance between the mean values of the parameters with normal distribution and homogeneous variance was tested with the t-Student test. For variables with non-Gaussian distributions or with different variances in the compared groups, non-parametric U Mann-Whitney test was used. For quality parameters we used $\chi^{2}$ test (Yates correction). Multiple linear regression was used to estimate the relationship between serology test result (the independent variable) and each of the cognitive measures (the dependent variables), taking into account such independent variables as age and sex, because of their possible influence on cognitive performance. Serology test result and sex are coded as 0 or 1 . In multivariable model of analysis the B-coefficient represents the difference in predicted measures of cognitive functions between seropositive and seronegative participants with adjustment for age and sex.

\section{RESULTS}

The study population consisted of 70 individuals, in 26 of them the level of IgG antibodies against Toxoplasma gondii was elevated. Their baseline characteristics and median values of cognitive testing results are presented in Table 1. A statistically significant association between increased level of anti- $T$. gondii antibodies and a lower
Table 1. Characteristics of the participants with positive and negative antibody test result.

\begin{tabular}{lcc}
\hline & $\begin{array}{c}\text { Positive antibody } \\
\text { test result }\end{array}$ & $\begin{array}{c}\text { Negative antibody } \\
\text { test result }\end{array}$ \\
\hline $\mathrm{N}$ & 26 & 44 \\
Age [years] & $31.4(8.4)$ & $24.9(5.1)$ \\
Gender - male/female & $6 / 20$ & $8 / 36$ \\
Cognitive performance: & & \\
TMT A & $19(15.8-24.5)$ & $19(16.5-23.0)$ \\
TMT B & $49(37.3-63.8)$ & $42(38.8-51.3)$ \\
Stroop Test I & $19.5(17.3-21.0)$ & $19(17.0-21.0)$ \\
Stroop Test II & $43(41.0-56.0)$ & $48(40.0-51.0)$ \\
Verbal Fluency Test & $39(35.5-41.8)$ & $43.5(38.0-55.0)$ \\
Digit Span - forwards & $6(5.3-7.8)$ & $6(5.0-8.0)$ \\
Digit Span - backwards & $7(6.0-8.0)$ & $7(6.0-8.3)$ \\
N-back Test - percentage & $92(76.0-100.0)$ & $96(88.0-100.0)$ \\
of correct answers & & \\
N-back Test - ration tim & $581.5(441.0-901.0)$ & $505.5(361.5-747.5)$ \\
\hline
\end{tabular}

N-back Test-reaction time 581.5 (441.0-901.0) 505.5 (361.5-747.5)

Data are means (SD) or median (25th-75th percentile).

score on N-back test (percentage of correct answers) was observed $(\beta-8.08 ; 95 \% \mathrm{CI}-15.64$ to $-0.53 ; \mathrm{p}<0.05)$. After adjustment for age and sex, no statistically significant associations between latent toxoplasmosis and the scores on any cognitive test were noticed (Table 2). A significant effect of age on cognitive performance was noted for TMT (part A and B), Digit Span - backwards, N-back test - reaction time. A significant relationship between sex and the score on Digit Span was also observed - male subjects performed this test better. Sex-dependent influence of latent toxoplasmosis on cognitive performance was also assessed. Taking into account interaction between toxoplasmosis and sex in their effect on cognitive function,

Table 2. $\beta$-coefficient for the relationship between cognitive test scores and antibody test result, age and sex.

\begin{tabular}{|c|c|c|c|c|c|}
\hline & \multirow{2}{*}{$\frac{\begin{array}{c}\beta \text {-coefficients in univariable } \\
\text { model }[95 \% \mathrm{CI}]\end{array}}{\text { Positive antibody test result }}$} & \multicolumn{4}{|c|}{$\beta$-coefficients in multivariable model $[95 \% \mathrm{CI}]$} \\
\hline & & Male sex & Age & $\begin{array}{l}\text { Positive antibody } \\
\text { test result }\end{array}$ & $\begin{array}{c}\text { Statistical } \\
\text { power }\end{array}$ \\
\hline TMT A & $\begin{array}{c}0.37 \\
{[-2.64 \text { to } 3.37]}\end{array}$ & $\begin{array}{c}1.92 \\
{[-1.63 \text { to } 5.47]}\end{array}$ & $\begin{array}{c}0.25^{*} \\
{[0.03 \text { to } 0.47]}\end{array}$ & $\begin{array}{c}-1.37 \\
{[-4.64 \text { to } 1.90]}\end{array}$ & 0.52 \\
\hline TMT B & $\begin{array}{c}5.73 \\
{[-1.34 \text { to } 12.79]}\end{array}$ & $\begin{array}{c}-2.48 \\
{[-10.64 \text { to } 5.69]}\end{array}$ & $\begin{array}{c}0.74 * * \\
{[0.23 \text { to } 1.25]}\end{array}$ & $\begin{array}{c}1.00 \\
{[-6.52 \text { to } 8.53]}\end{array}$ & 0.84 \\
\hline Stroop I & $\begin{array}{c}0.17 \\
{[-1.20 \text { to } 1.55]}\end{array}$ & $\begin{array}{c}-0.89 \\
{[-2.52 \text { to } 0.74]}\end{array}$ & $\begin{array}{c}0.10 \\
{[0.00 \text { to } 0.20]}\end{array}$ & $\begin{array}{c}-0.43 \\
{[-1.93 \text { to } 1.08]}\end{array}$ & 0.47 \\
\hline Stroop II & $\begin{array}{c}1.78 \\
{[-3.02 \text { to } 6.59]}\end{array}$ & $\begin{array}{c}-3.48 \\
{[-9.17 \text { to } 2.21]}\end{array}$ & $\begin{array}{c}0.34 \\
{[-0.01 \text { to } 0.69]}\end{array}$ & $\begin{array}{c}-0.28 \\
{[-5.53 \text { to } 4.96]}\end{array}$ & 0.54 \\
\hline Verbal Fluency Test & $\begin{array}{c}-5.01 \\
{[-10.88 \text { to } 0.86]}\end{array}$ & $\begin{array}{c}1.73 \\
{[-5.50 \text { to } 8.95]}\end{array}$ & $\begin{array}{c}-0.06 \\
{[-0.51 \text { to } 0.39]}\end{array}$ & $\begin{array}{c}-4.72 \\
{[-11.37 \text { to } 1.94]}\end{array}$ & 0.29 \\
\hline Digit Span - forwards & $\begin{array}{c}0.30 \\
{[-0.75 \text { to } 1.35]}\end{array}$ & $\begin{array}{c}1.51^{*} \\
{[0.29 \text { to } 2.74]}\end{array}$ & $\begin{array}{c}-0.04 \\
{[-0.12 \text { to } 0.04]}\end{array}$ & $\begin{array}{c}0.49 \\
{[-0.64 \text { to } 1.62]}\end{array}$ & 0.66 \\
\hline Digit Span - backwards & $\begin{array}{c}-0.14 \\
{[-1.33 \text { to } 1.04]}\end{array}$ & $\begin{array}{c}1.99 * * \\
{[0.73 \text { to } 3.25]}\end{array}$ & $\begin{array}{c}-0.13^{* *} \\
{[-0.20 \text { to }-0.05]}\end{array}$ & $\begin{array}{c}0.59 \\
{[-0.57 \text { to } 1.76]}\end{array}$ & 0.99 \\
\hline $\begin{array}{l}\text { N-back Test - percent- } \\
\text { age of correct answers }\end{array}$ & $\begin{array}{c}-8.08^{*} \\
{[-15.64 \text { to }-0.53]}\end{array}$ & $\begin{array}{c}4.17 \\
{[-4.95 \text { to } 13.30]}\end{array}$ & $\begin{array}{c}-0.38 \\
{[-0.97 \text { to } 0.20]}\end{array}$ & $\begin{array}{c}-5.78 \\
{[-14.18 \text { to } 2.63]}\end{array}$ & 0.62 \\
\hline $\begin{array}{l}\text { N-back Test-time } \\
\text { reaction }\end{array}$ & $\begin{array}{c}79.01 \\
{[-72.98 \text { to } 231.00]}\end{array}$ & $\begin{array}{c}-129.94 \\
{[-298.31 \text { to } 38.51]}\end{array}$ & $\begin{array}{c}18.40^{* * *} \\
\text { [7.96 to } 28.84 \text { ] }\end{array}$ & $\begin{array}{c}-35.35 \\
{[-190.50 \text { to } 119.80]}\end{array}$ & 0.95 \\
\hline
\end{tabular}

$\beta$-coefficient is the regression coefficient. The first column contains the values of $\beta$ in the univariable analysis. The next three columns contain the values of $\beta$ for each of independent variables (multivariable analysis). $95 \% \mathrm{CI}-95 \%$ confidence interval for a regression coefficient. In case of TMT, Stroop Test, N-back (time reaction) B $>0$ means worse score. In case of Verbal Fluency Test, Digit Span, N-back (percentage of correctness) B $>0$ means better score. ${ }^{*} \mathrm{p}<0.05 ; * * \mathrm{p}<0.01 ; * * * \mathrm{p}<0.001$. 


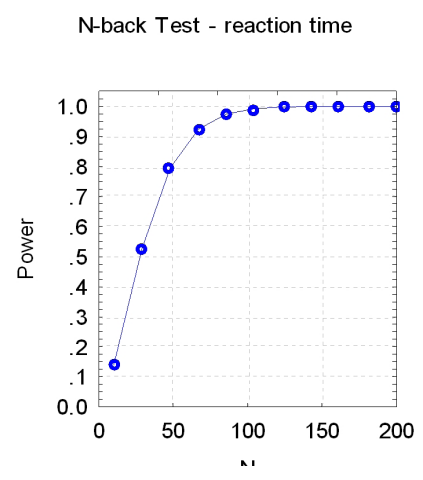

TMT B

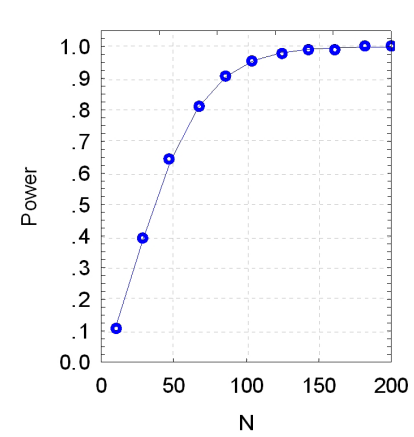

Verbal Fluency Test

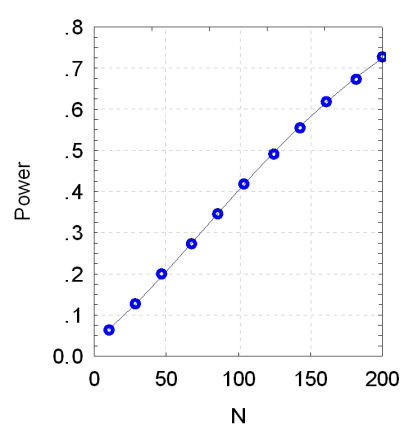

$\mathrm{N}$-back Test - percentage of correct answers

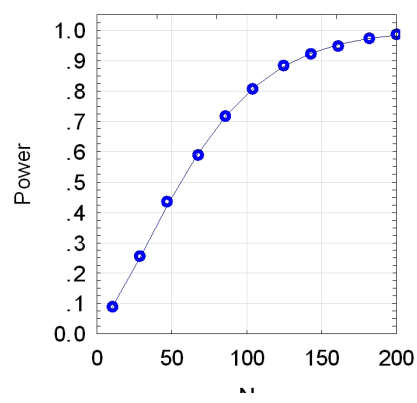

Stroop I

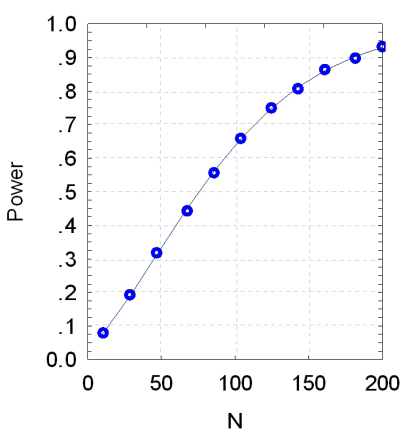

Digit Span - forwards

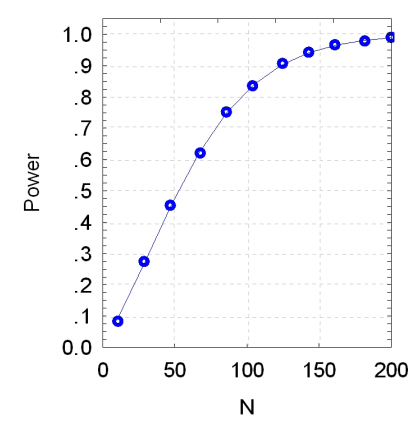

TMT A

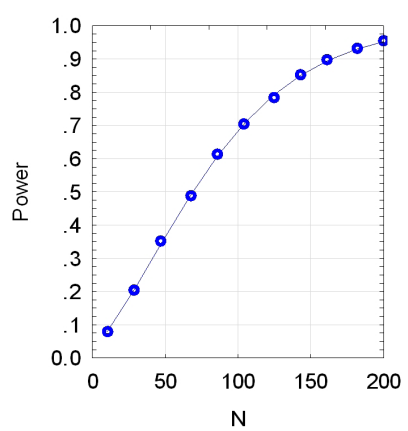

Stroop II

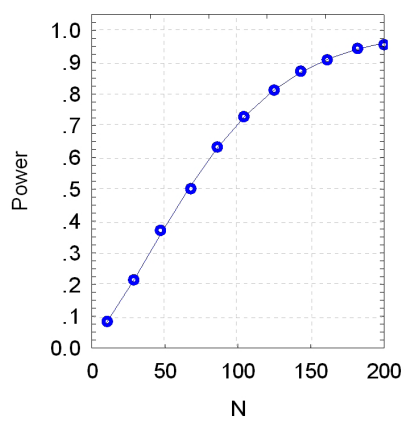

Digit Span - backwards

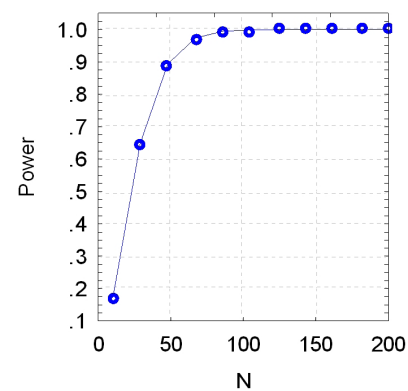

Fig. 1. Effect of group size on the power of the test. Statistical power $(1-\beta)$ is computed as a function of significance level $\alpha$, sample size, and population effect size (Cohen 1988, Faul et al. 2007).

no significant differences were observed. The computed values of statistical power are included in Table 2. Power analysis, that shows effect of sample size on the power of the test, is presented in Fig. 1.

\section{DISCUSSION}

In this paper our purpose was to ascertain whether chronic, latent, subclinical Toxoplasma gondii infection is related to cognitive performance. No such research using the large battery of cognitive tests to study this kind of association was performed before. However, some studies suggest the influence of $T$. gondii chronic infection on reduced cognitive functioning. Flegr et al. (2009) described an increased incidence of traffic accidents in T. gondii-infected drivers. The possible reason for this phenomenon is the impaired reaction time noticed in another study (Havlíček et al. 2001). TMT and N-back test are related to psychomotor speed (Strauss et al. 2006). No correlations between latent toxoplasmosis and performance on these tests were manifested.

There are studies that prove an association between latent toxoplasmosis and schizophrenia, suggesting an involvement of this parasite in the aetiology of this disorder. Elevated anti-T. gondii IgG antibodies level was noticed in patients with first-onset schizophrenia (Wang et al. 2006). At that time patients were in the chronic stage of infection, which was established by examining the levels of anti-T. gondii IgM antibody.

Researchers observed some differences in personality and temperament profile between Toxoplasma-positive and Toxoplasma-negative subjects (Flegr et al. 2000, 2003, Skallová et al. 2005). Infected subjects had lower novelty seeking scores in Cloninger's Temperament and Character Inventory, they also had lower IQ and lower 
probability of gaining post-secondary education (Flegr et al. 2003). Decrease in novelty seeking suggests an influence of chronic infection on neurotransmission, especially dopaminergic transmission. This hypothesis was also studied by observing difference in effect of selective dopamine uptake inhibitor on alterations in mice behaviour induced by T. gondii (Skallová et al. 2006). Changes in dopaminergic transmission could explain the influence of $T$. gondii chronic infection on personality profile and pathogenesis of schizophrenia. However, can this mechanism be responsible for cognitive impairment?

Dopaminergic transmission is involved in cognitive processes (Schnider et al. 2010) The role of connections between prefrontal cortex and striatum and monoaminergic modulation within this circuit has been studied in the context of cognitive flexibility (Kehagia et al. 2010). Prefrontal cortex is the principal part of the operative memory system which operates optimally within a limited range of dopamine transmission. Areas of prefrontal cortex are engaged in Trail Making Test part B, Verbal Fluency Test, Stroop Test II, N-back Test (Strauss et al. 2006). A statistically important relationship between latent toxoplasmosis and the cognitive performance in any of these tests was not observed in our study, so we could not confirm that chronic $T$. gondii infection affects prefrontal cortex-depending cognitive functions.

Another way in which $T$. gondii chronic infection can influence brain functions is the induction of immunological reaction towards the dormant cysts of the parasite located in the neural tissue. In mice, chronic T. gondii infection acquired during adulthood causes neurological and behavioural abnormalities secondary to inflammation and neurodegeneration (Hermes et al. 2008). Presence of perivascular and diffuse parenchymal infiltration in frontal cortex and diencephalon has also been noticed. Some changes in host gene expression profiles were observed in human fibroblasts infected by tachyzoites. The capacity of such cells to activate immune responses was also proven (Blader et al. 2001). However, in this research influence of latent Toxoplasma infection on brain functions is not confirmed.

It was also found that psychological and cognitive responses to toxoplasmosis differ depending on $\mathrm{Rh}$ blood group. Studies showed Rh-positive subjects are protected against the $T$. gondii-induced changes of reaction times (Flegr et al. 2008, Novotná et al. 2008) and increased risk of traffic accidents (Flegr et al. 2009). Flegr et al. (2010) described the opposite effects of toxoplasmosis on some personality factors in Cloninger's TCI questionnaire in $\mathrm{Rh}$-positive and Rh-negative subjects. $\mathrm{RhD}$ antigen is present in a majority of the Caucasian population. Rh group of the participants was not marked in this study. However, only $15 \%$ Polish population is RhD-negative. Taking this data into account, it could be hypothesized that majority of participants in this study is protected against possible cognitive changes induced by toxoplasmosis. This may be also a possible reason why significant differences between $T$. gondii-infected and T. gondii-free subjects were not observed.

Our study had several limitations. Firstly, there was a disparity of the participant amount in two groups, reflected in a small number of individuals with elevated level of anti-T. gondii IgG antibodies. Low number of participants in the study results in low power of statistical analysis. Another limitation is the average age of participants. Some studies noticed that the effect of chronic toxoplasmosis on cognitive functioning and behavioural changes is slow and cumulative (Flegr et al. 2000, Havlíček et al. 2001). We studied individuals who were from 21 to 53 years of age; the average age was 24.9 in seronegative group and 31.4 in seropositive group. It would be advisable to study the relationship between latent toxoplasmosis and cognition in older individuals. Moreover, it was impossible in this study to obtain the information about length of infection. There is a lack of simple reaction time test in the battery of cognitive tests, though TMT and N-back test are related to psychomotor speed (Strauss et al. 2006). This makes the comparison with results of other studies of psychomotor speed in patients with toxoplasmosis more difficult. Prevalence of female participants may have also biassed the results.

In conclusion, we obtained no evidence that chronic latent $T$. gondii infection affects cognitive function. This is the first research assessing this relationship using a battery of cognitive tests examining such complex processes as working memory and executive functions. Although the impact of infection on psychiatric, behavioural and cognitive state was observed in earlier studies, our findings could not confirm that chronic $T$. gondii infection influences brain function in terms of cognitive dysfunction. This issue requires further evaluation by studies with a larger sample.

\section{REFERENCES}

Alford C.A. Jr., Stagno S., Reynolds D.W. 1974: Congenital toxoplasmosis: clinical laboratory and therapeutic considerations, with special reference to subclincial disease. Bull. N. Y. Acad. Med. 50: 160-181.

Blader I.J., Manger I.D., Boothroyd J.C. 2001: Microarray analysis reveals previously unknown changes in Toxoplasma gondii infected human cells. J. Biol. Chem. 276: 24223-24231.
Caiaffa W.T., Chiari C.A., Figueiredo A.R., Orefice F., AnTUNES C.M. 1993: Toxoplasmosis and mental retardation report of a case-control study. Mem. Inst. Oswaldo Cruz 88: 253-261.

Cetinkaya Z., Yazar S., Gecici O., Namli M.N. 2007: AntiToxoplasma gondii antibodies in patients with schizophrenia - preliminary findings in a Turkish sample. Schizophr. Bull. 33: 789-791. 
Cohen J. 1988: Statistical power analysis for the behavioral sciences. 2nd edition. L. Erlbaum Associates, Hillsdale, New Jersey, 567 pp.

Faul F., Erdfelder E., Lang A.G., Buchner A. 2007: G*Power 3: a flexible statistical power analysis program for the social, behavioral, and biomedical sciences. Behav. Res. Methods 39: 175-191.

Fekadu A., Shibre T., Cleare A.J. 2010: Toxoplasmosis as a cause for behaviour disorders - overview of evidence and mechanisms. Folia Parasitol. 57: 105-113.

Flegr J., Hrdý I. 1994: Influence of chronic toxoplasmosis on some human personality factors. Folia Parasitol. 41: 122-126.

Flegr J., Klose J., Novotná M., Berenreitterová M., Havlíček J. 2009: Increased incidence of traffic accidents in Toxoplasmainfected military drivers and protective effect RhD molecule revealed by a large-scale prospective cohort study. BMC Infect. Dis. 9: e72.

Flegr J., Kodym P., Tolarová V. 2000: Correlation of duration of latent Toxoplasma gondii infection with personality changes in women. Biol. Psychol. 53: 57-68.

Flegr J., Novotná M., Fialová A., Kolbeková P., Gašová Z. 2010: The influence of RhD phenotype on toxoplasmosis- and age-associated changes in personality profile of blood donors. Folia Parasitol. 57: 143-150.

Flegr J., Novotná M., Lindová J., HavlíčeK J. 2008: Neurophysiological effect of the Rh factor. Protective role of the RhD molecule against Toxoplasma-induced impairment of reaction times in women. Neuroendocrinol. Lett. 29: 475-481.

Flegr J., Preiss M., Klose J., Havlíček J., Vitáková M., Kodym P. 2003: Decreased level of psychobiological factor novelty seeking and lower intelligence in men latently infected with the protozoan parasite Toxoplasma gondii. Dopamine, a missing link between schizophrenia and toxoplasmosis? Biol. Psychol. 63: 253-268.

Havlíček J., Gašová Z.G., Smith A.P., Zvára K., Flegr J. 2001: Decrease of psychomotor performance in subjects with latent 'asymptomatic' toxoplasmosis. Parasitology 122: 515-520.

Hay J., Aitken P.P., Hutchison W.M., Graham D.I. 1983: The effect of congenital and adult-acquired Toxoplasma infections on activity and responsiveness to novel stimulation in mice. Ann. Trop. Med. Parasitol. 77: 483-495.

Hermes G., Ajioka J.W., Kelly K.A., Mui E., Roberts F., Kasza K., Mayr T., Kirisits M.J., Wollmann R., Ferguson D.J., Roberts C.W., Hwang J.H., Trendler T., Kennan R.P., Suzuki Y., Reardon C., Hickey W.F., Chen L., McLeod R. 2008: Neurological and behavioural abnormalities, ventricular dilatation, altered cellular functions, inflammation, and neuronal injury in brains of mice due to common, persistent, parasitic infection. J. Neuroinflammation 5: e48.

Jones J.L., Kruszon-Moran D., Sanders-Lewis K., Wilson M. 2007: Toxoplasma gondii infection in the United States, 1999-2004, decline from the prior decade. Am. J. Trop. Med. Hyg. 77: 405-410.

Kannan G., Moldovan K., Xiao J.C., Yolken R.H., JonesBrando L., Pletnikov M.V. 2010: Toxoplasma gondii straindependent effects on mouse behaviour. Folia Parasitol. 57: 151-155.

Kehagia A.A., Murray G.K., Robbins T.W. 2010: Learning and cognitive flexibility: frontostriatal function and monoaminergic modulation. Curr. Opin. Neurobiol. 20: 199-204.

Lyons R.E., McLeod R., Roberts C.W. 2002: Toxoplasma gondii tachyzoite-bradyzoite interconversion. Trends Parasitol. 18: 198-201.
Markell E.K., John D.T., Krotoski W.A. 1999: Markell and Voge's Medical Parasitology. 8th edition. W.B. Saunders Company, Philadelphia, 501 pp.

Miman O., Mutlu E.A., Ozcan O., Atambay M., Karlidag R., UnAL S. 2010: Is there any role of Toxoplasma gondii in the etiology of obsessive-compulsive disorder? Psychiatry Res. 177: 263-265.

Montoya J.G., Liesenfeld O. 2004: Toxoplasmosis. Lancet 363: 1965-1976.

Niemiec K.T., Raczyński P., Markiewicz K., Leibschang J., CERAN A. 2002: The prevalence of Toxoplasma gondii infection among 2016 pregnant women and their children in the Institute of Mother and Child in Warsaw. Wiad. Parazytol. 48: 293-299. (In Polish with English abstract.)

Novotná M., Havlíček J., Smith A.P., Kolbeková P., Skallová A., Klose J., Gašová Z., Písačka M., Sechovská M., Flegr J. 2008: Toxoplasma and reaction time: role of toxoplasmosis in the origin, preservation and geographical distribution of $\mathrm{Rh}$ blood group polymorphism. Parasitology 135: 1253-1261.

Remington J.S., Krahenbuhl J.L. 1982: Immunology of Toxoplasma gondii. In: A.J. Nahmias and J. O’Reilly (Eds.), Immunology of Human Infection. Part II. Plenum Publishing Corporation, New York, pp. 327-371.

Schnider A., Guggisberg A., Nahum L., Gabriel D., Morand S. 2010: Dopaminergic modulation of rapid reality adaptation in thinking. Neuroscience 167: 583-587.

Skallová A., Kodym P., Frynta D., Flegr J. 2006: The role of dopamine in Toxoplasma-induced behavioural alterations in mice: an ethological and ethopharmacological study. Parasitology 133: 525-535.

Skallová A., Novotná M., Kolbeková P., Gašová Z., Veselý V., Sechovská M., Flegr J. 2005: Decreased level of novelty seeking in blood donors infected with Toxoplasma. Neuroendocrinol. Lett. 26: 480-486.

STiввs H.H. 1985: Changes in brain concentrations of catecholamines and indoleamines in Toxoplasma gondii infected mice. Ann. Trop. Med. Parasitol. 79: 153-157.

Strauss E., Sherman E.M., Spreen O. 2006: A Compendium of Neuropsychological Tests: Administration, Norms, and Commentary. 3rd edition. Oxford University Press, Oxford, 1216 pp.

Tamer G.S., Dundar D., Yalug I., Caliskan S., Yazar S., Aker A. 2008: The schizophrenia and Toxoplasma gondii connection: infectious, immune or both? Adv. Ther. 25: 703-709.

Tenter A.M., Heckeroth A.R., Weiss L.M. 2000: Toxoplasma gondii: from animals to humans. Int. J. Parasitol. 30: 1217-1258.

Vyas A., Kim S.K., Giacomini N., Boothroyd J.C., Sapolsky R.M. 2007: Behavioural changes induced by Toxoplasma infection of rodents are highly specific to aversion of cat odors. Proc. Natl. Acad. Sci. U.S.A. 104: 6442-6447.

Wang H.L., Wang G.H., Li Q.Y., Shu C., Jiang M.S., Guo Y. 2006: Prevalence of Toxoplasma infection in first-episode schizophrenia and comparison between Toxoplasma-seropositive and Toxoplasma-seronegative schizophrenia. Acta Psychiatr. Scand. 114: 40-48.

Webster J.P., Brunton C.F., Macdonald D.W. 1994: Effect of Toxoplasma gondii on neophobic behaviour in wild brown rats, Rattus norvegicus. Parasitology 109: 37-43.

Witting P.A. 1979: Learning capacity and memory of normal and Toxoplasma-infected laboratory rats and mice. Z. Parasitenkd. 61: 29-51.

Yereli K., BalcioĞlu I.C., OzBilgin A. 2006: Is Toxoplasma gondii a potential risk for traffic accidents in Turkey? Forensic Sci. Int. 163: 34-37. 